\title{
Water Expert: a conceptualized framework for development of a rule-based decision support system for distribution system decontamination
}

\author{
J. L. Gutenson ${ }^{1}$, A. N. S. Ernest ${ }^{1}$, J. R. Fattic ${ }^{2, a}$, L. E. Ormsbee ${ }^{3}$, A. A. Oubeidillah ${ }^{1}$, and X. Zhang ${ }^{1}$ \\ ${ }^{1}$ The University of Alabama, Tuscaloosa, Alabama \\ ${ }^{2}$ Western Kentucky University, Bowling Green, Kentucky \\ ${ }^{3}$ University of Kentucky, Lexington, Kentucky \\ ${ }^{a}$ now at: Akebono Brake Corporation, Glasgow, Kentucky
}

Correspondence to: J. L. Gutenson (jlgutenson@eng.ua.edu)

Received: 1 May 2014 - Published in Drink. Water Eng. Sci. Discuss.: 27 May 2014

Revised: 29 June 2015 - Accepted: 17 August 2015 - Published: 28 August 2015

\begin{abstract}
Significant drinking water contamination events pose a serious threat to public and environmental health. Water utilities often must make timely, critical decisions without evaluating all facets of the incident. The data needed to enact informed decisions are inevitably dispersant and disparate, originating from policy, science, and heuristic contributors. Water Expert is a functioning hybrid decision support system (DSS) and expert system framework that emphasizes the meshing of parallel data structures in order to expedite and optimize the decision pathway. Delivered as a thin-client application through the user's web browser, Water Expert's extensive knowledgebase is a product of inter-university collaboration that methodically pieced together system decontamination procedures. Decontamination procedures are investigated through consultation with subject matter experts, literature review, and prototyping with stakeholders. This paper discusses the development of Water Expert, analyzing the development process underlying the DSS and the system's existing architecture specifications. Water Expert constitutes the first system to employ a combination of deterministic and heuristic models which provide decontamination solutions for water distribution systems. Results indicate that the decision making process following a contamination event is a multi-disciplinary effort. This contortion of multiple inputs and objectives limit the ability of the decision maker to find optimum solutions without technological intervention.
\end{abstract}

\section{Introduction}

Decontamination decisions made following contamination events for water distribution networks (WDNs) are a complex entanglement of empirical practices. Solutions are selected through heuristic solution processes. Oftentimes in such events, a lack of synthesized information does not afford the decision maker with the ability to rationally determine the optimum remediation and recovery strategy. The data needed in the decision making progression can be supplied through field observations, mathematical models, regulatory requirements, and organizational policy. These data vary both spatially and conceptually, as science and policy from the local, state, and federal scales are pooled to produce conclusions. Coalescing these diverse sources of data into usable information presents a challenge. Thus, to make a timely decision, the managers of WDNs are unlikely to take into account all characteristics of the emergency situation. In this regard, web-delivered information systems, driven by artificial intelligence (AI) such as expert systems, provide a means by which to supply the decision maker with recommendations. The expert system compiles divergent data sources within an integrated decision support system platform. The Water Expert system framework, a hybrid DSS with expert system capabilities, provides such a means. Developed by a consortium of universities, this application provides integrated decision making tools that are driven by all of the identified data inputs and presented to the user through his or her local 
web browser. Integrated with KYPipe's Network Decontamination Model (NDM), data can be acquired from third party applications, uploaded into Water Expert via the internet, and used to drive Water Expert recommendations and actions.

Water Expert provides recommendations for decontamination of WDNs using regulatory requirements, manuals of practice, academic and trade association journals, and industry-established procedures. This knowledge was gathered from a series of tabletop, technology demonstration, and technology deployment workshops hosted by the investigating consortium. This system can be dynamically augmented to include other knowledge domains such as local and state regulations as needed. Further, additional third-party applications can similarly be linked into Water Expert, either replacing or augmenting its standard toolset.

This paper describes the groundwork for the Water Expert concept and the decision making process undertaken during contamination events. Primarily, the current methodology of decision making during WDN emergency operations, how Water Expert augments this process, and the technical and contextual composition of Water Expert are described. A case study with a small WDN will demonstrate the system's current capacity. Finally, a discussion of the future vision for the Water Expert platform will follow. The core of this research addresses how computational and heuristic tools can be coalesced to address contamination incidents in WDNs. In addition, the authors elicit insight from the process by which utilities typically decontaminate their networks.

\section{Literature review}

Decontamination procedures are critical to successful water system recovery following a contamination event. They have repeatedly been highlighted as a significant issue for the water sector by the numerous working groups and councils that have strategized and formulated the most appropriate courses of action (Water Sector Coordinating Council, 2007; Water Sector Decontamination Workshop, 2008). In addition, governmental agencies such as the US Environmental Protection Agency (USEPA), and trade associations such as the American Water Works Association (AWWA) and the Water Research Foundation (WRF), develop and maintain guidance documents (USEPA, 2012; Water Research Foundation, 2009), case studies (USEPA, 2008; Murray et al., 2010), and tools (Sandia National Laboratories, 2010; USEPA, 2013a, $2014 \mathrm{~b}, \mathrm{c})$ that are intended to enhance water infrastructure resiliency to contamination events.

Of particular interest to those in the United States, the USEPA has published a series of guides, collectively known as the Response Protocol Toolbox (USEPA, 2003a, c, d, e, f; 2004b, c, d), for addressing security and protection of the drinking water and wastewater sectors. The USEPA actively maintains the Threat Ensemble Vulnerability Assessment (TEVA) program (Murray et al., 2004). However, syn- thesized information for water systems to make informed decisions regarding decontamination of compromised drinking water systems is lacking. This disconnect exists because disparate sources of information cloud the resolution process. No preexisting software application provides utility managers and planners with recovery guidance after a contamination event. Therefore, a significant disconnect remains between the numerical modeling applications, such as EPANET2, and taking the appropriate course of action during contamination episodes. Appropriate decontamination procedures are further contorted by the actions incorporated at the individual utility level, through site-specific Vulnerability Assessments (USEPA, 2002a, c), Emergency Response Plans (ERPs) (USEPA, 2003b, 2004a), and Sanitary Surveys (USEPA, 1995, 2001).

Vulnerability assessments include a series of analyses: (1) a review of pipes and constructed conveyances; (2) physical barriers; (3) water collection, pretreatment, treatment, storage and distribution facilities; (4) electronic, computer or other automated systems which are utilized by the public water system; (5) the use, storage, or handling of various chemicals; and the operation and maintenance of the system. ERPs include plans, procedures, and identification of equipment that can be implemented or utilized in the event of a terrorist or other intentional attack on the public water system. The ERP also includes actions, procedures, and identification of equipment which can prevent or significantly lessen the impact of terrorist attacks or other intentional actions on public health and safety and the supply of drinking water provided to communities and individuals. Sanitary surveys review a water system's source water (identifying sources of contamination using results of source water assessments where available), facilities, equipment, operation, maintenance and monitoring compliance in order to evaluate the adequacy of the system, its sources and operations, and the distribution of safe drinking water. The findings from these efforts at the local level are paired with information produced by government and trade associations and provided to output decision models for contamination events.

Artificial intelligence (AI), in the form of computer algorithms, have successfully been applied to bridge the gap between data acquisition and heuristic decision making. AI has been used extensively in the industrial sector (Fonseca et al., 2003; Delen and Pratt, 2006; Moynihan, 2004; Moynihan et al., 2006) and business community (Ahn et al., 2000; Nemati et al., 2002; Bahrammirzaee, 2010; Shen et al., 2011) to turn data into knowledge. AI application has also migrated into additional disciplines, including the water industry, where it has been demonstrated as an aid to modeling water quality (Panda et al., 2004; Purkait et al., 2008; Kisi et al., 2013) estimating water quantity (Nourani et al., 2012), predicting wastewater treatment performance (Rene et al., 2008), and optimizing distribution system design (Suribabu and Neelakantan, 2006). Thus, AI demonstrates tremendous, crossdisciplinary functionality in decision support. 
Expert systems are a form of AI designed to mimic the decision making faculties of human experts. As AI inherently mimics human intelligence, expert systems replicate the intelligence of the human expert (Engelmore and Feigenbaum, 1993). Expert systems are commonly composed of three modules: a knowledgebase, inference engine, and user interface. The fact base represents a composition of knowledge broken down into its most fundamental form. The rule base describes the interaction between different facts. The fact base and rule base form if-then conditional relationships and compose the knowledgebase. The knowledgebase consists of knowledge acquired from models, sensors, the literature, experts, and the user. The inference engine drives the interaction between the user, rule base, and fact base. The user interface provides the user a means of interaction with the system (Feinsten and Hadden, 1989). Interaction is typically accomplished through the system asking the user a series of questions. Thus, the interaction resembles a conversation between a user and a human expert.

Expert systems have been used to improve distribution system performance and provide recommendations for sensor placement in water distribution networks. Sandeep and Rakesh (2011) demonstrate that expert systems are an effective means of improving the performance of aging distribution systems through the linkage of heuristic and mechanistic models. In particular, Sandeep and Rakesh have shown that the C Language Integrated Production System (CLIPS) is an effective expert system shell in distribution system contexts. Chang et al. (2012a, b) successfully used rule-based decision support for guidance in optimum sensor placement across large and small scale distribution systems. This research indicated that the functional capacity is adaptable to both large and small systems. These examples demonstrate scalable rule based, expert system capability in drinking water decision support in management, maintenance, and emergency scenarios. In this optic, The University of Alabama, Western Kentucky University, The University of Kentucky, the University of Missouri, and the University of Louisville teamed together and developed an analysis and decision support system named Water Expert. Water Expert includes an expert system shell and provides guidance to water sector owners and operators for the decontamination of water systems after a significant chemical or biological agent propagates within their distribution system. This tool differs from those developed by the USEPA in that it unites computational tools with heuristic decision making in order to provide the user with recommendations on appropriate decontamination strategies.

Water Expert provides guidance to local, state, and regional water system owners and operators during their initial response and subsequent decision making regarding contaminated water systems. The system provides guidance by incorporating information acquired through literature reviews, tabletop exercises, and technology demonstration and deployment workshops conducted by each participating univer- sity into a knowledgebase. Water Expert includes both graphical tools and user-assisted menus for helping water system personnel select the appropriate course of action relative to the nature and extent of contamination. This tool uses the Network Decontamination Model (NDM), a modular extension to the hydraulic modeling software KYPipe. The NDM identifies what valves need to be closed to isolate a particular pipe. It calculates the associated volume of water that may have to be remediated and identifies hydrants that are connected to the contaminated section. The NDM also determines whether closing different valves will causes pressure changes within the system (KYPipe and University of Kentucky, 2012; KYPipe, 2014).

Water Expert then generates a local fact base derived from the user and compares the fact base to the knowledgebase using a pattern matching, inference engine. Interaction with this system occurs through an online Content Management System (CMS), Drupal 6 (Drupal, 2008), embedded with the expert system shell, (CLIPS, 2013). Water Expert generates warnings regarding the public and environmental health effects of a contaminant. It also informs the user if contaminant concentration exceeds both drinking water and source water regulatory concentrations. Additionally, the system offers recommendations for the most effective treatment technologies, including detailed procedures and recommendations and provides fact sheets on common contaminants.

The tool has the ability to integrate third party applications, including EPANET2 and Geographic Information System (GIS) data. It also provides the adaptive extensibility needed to refine the system to meet the needs of individual utilities.

With this framework, the meshing of heuristic decision making and numerical measurement is accomplished by gaining perspective on how decontamination decisions are currently made. The following sections detail how the knowledge domains in Water Expert were developed and intertwined with the computational, regulatory, trade association, and academic knowledge domains. This accomplishment represents the first instance of combining heuristic knowledge with computational tools to provide assistance to WDNs during contamination events. The design of the system encompasses the numerous disciplines that guide final decisions. Thus, the decision making process was fully investigated when developing Water Expert. The process of designing Water Expert looked to examine three specific research questions: (1) what is the current decision process undertaken by water utilities during contamination events? (2) Can a computer system design encompass the decision needs of contaminated distribution systems? (3) Can we combine heuristic decision making with existing distribution system computational models? 


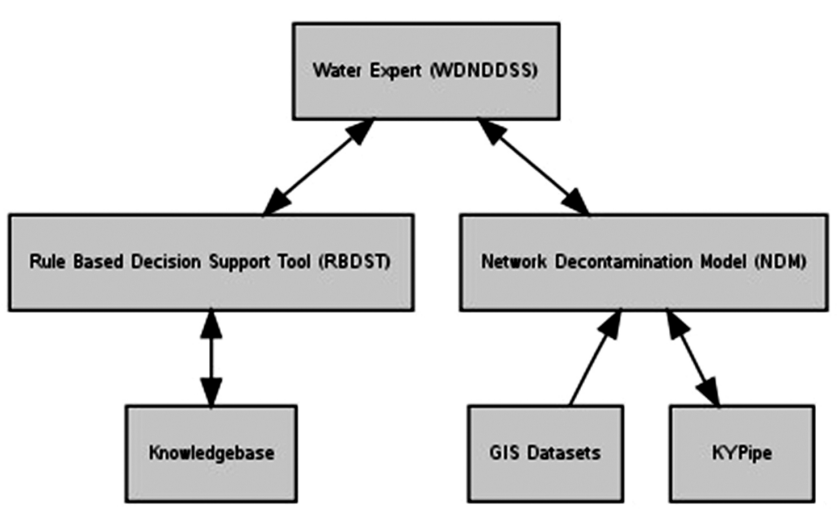

Figure 1. Flow diagram of the Water Expert system.

\section{Methodology}

Water Expert is a product coalesced from research conducted at six water research and development centers at five participating universities; research by the participating entities eventually amalgamated and comprised the architecture of WDNDDSS. Figure 1 illustrates the flow of the system.

The Water Resources Research Center and the Community Policy Analysis Center at the University of Missouri conducted a literature review that elicited a large portion of the Knowledgebase of Guidance Rules depicted in Fig. 1. The CIR at the University of Louisville conducted a series of tabletop exercises that examined the decision-making practices of key agencies involved in decontamination, further feeding the Knowledgebase. The KWRRI at The University of Kentucky and KYPipe partnered to develop the Network Decontamination Model (NDM), where GIS data and KYPipe were integrated to provide visualization and analysis tools to feed data into Water Expert.

These projects then coalesced within the Water Expert system framework by the EI at The University of Alabama and CWRS at Western Kentucky University. This meshing provides an integrated, novel platform with which utilities make timely and informed decisions on how to best decontaminate their distribution system. CWRS and EI hosted a series of technology demonstration workshops in which utility administrators and regional planners examined the final product. Three participating utilities then hosted a subsequent round of technology deployment workshops in order to display the final product. Each research product provides intelligence regarding the current decision making process during WDN contamination events. Thus, the following text provides insight into the current decision paradigm. Further, Water Expert addresses how to effectively combine heuristic decision making and mathematical model outputs to assist WDN decontamination processes. To determine the validity of such software, researchers queried academic literature, consulted water utilities, and developed a computational tool. The fol- lowing sections detail how each of these objectives were accomplished.

\subsection{Literature review and state of the art decontamination report}

The Water Resources Research Center and the Community Policy Analysis Center at the University of Missouri conducted an extensive literature review of government and research databases. This review examined the current methodology and technology available for decontaminating drinking water systems. Examination produced a robust knowledge domain for validating decontamination strategies.

With the inception of the Bioterrorism Act of 2002 and the Homeland Security Presidential Directive 7 (HSPD 7), the USEPA took charge in facilitating resilient water infrastructure (US Department of Homeland Security, 2003; USEPA, 2002b). The USEPA then produced a series of guidance documents and tools for utilities to utilize in order to improve their contamination resiliency. These guidance documents form the girth of fused information currently available for contamination prevention and recovery. These products included detailed systematic methodologies for response and recovery during contamination events (USEPA, 2003a, c, d, e, f, 2004b, c, d), guidelines for preparing Emergency Response Plans (USEPA, 2003b, 2004a), procedures for preparing vulnerability assessments (USEPA, 2002a, c), and a database of contaminants that pose significant threat to water systems (USEPA, 2013a). In particular, Module 6 of the USEPA Response Protocol Toolbox provided a consolidated table of treatment technologies and their effectiveness in treating broad classifications of contaminant species. Table 1 presents a variation (USEPA, 2004c).

Review of publicly available research databases, such as Academic Search Premier and Scopus, provided additional detailed knowledge concerning the decontamination process. Researchers reviewed and condensed relevant literature item into a concise summary. This search found nearly 900 pieces of relevant literature with information on technologies and methodologies pertinent to the decontamination of a water system.

Overall, results indicated that the course a utility takes towards decontamination will likely depend upon factors including contaminant characteristics, distribution system characteristics, volume of effected water, extent of the contamination, and resources available for response. Water Expert's design considers these decision making characteristics.

\subsection{Tabletop exercise}

The CIR at the University of Louisville hosted a workshop involving utilities, emergency responders, and other stakeholders in order to gain perspective on the relevant decision points in making an informed decontamination decision. These sessions follow the tabletop exercise format developed 
Table 1. Technologies used to decontaminate water and their relative effectiveness, adapted from USEPA Module 6: Response and Recovery Guide (USEPA, 2004c).

\begin{tabular}{|c|c|c|c|c|c|}
\hline Technology & $\begin{array}{l}\text { Inorganic } \\
\text { Chemicals }\end{array}$ & Microbes & Radionuclides & $\begin{array}{l}\text { Non-volatile Organic } \\
\text { Chemicals }\end{array}$ & $\begin{array}{l}\text { Volatile Organic } \\
\text { Chemicals }\end{array}$ \\
\hline Activated Alumina & More Effective & Not Effective & More Effective & Insufficient Data & Insufficient Data \\
\hline Activated Carbon & Less Effective & Insufficient Data & Less Effective & More Effective & More Effective \\
\hline Air Stripping & Not Effective & Not Effective & Not Effective & Not Effective & Less Effective \\
\hline Chloramination & Insufficient Data & Less Effective & Not Effective & Insufficient Data & Insufficient Data \\
\hline Chlorination & Less Effective & More Effective & Not Effective & Insufficient Data & Less Effective \\
\hline Chlorine Dioxide & Less Effective & More Effective & Not Effective & Insufficient Data & Less Effective \\
\hline Coagulation/Filtration & Less Effective & More Effective & Not Effective & Less Effective & Not Effective \\
\hline Direct Filtration & Insufficient Data & More Effective & Insufficient Data & Insufficient Data & Insufficient Data \\
\hline Ion Exchange & More Effective & Not Effective & More Effective & Not Effective & Not Effective \\
\hline Microfiltration/Ultrafiltration & Not Effective & Insufficient Data & More Effective & Insufficient Data & Not Effective \\
\hline Ozonation & Less Effective & More Effective & Not Effective & Less Effective & Less Effective \\
\hline Reverse Osmosis/Ultrafiltration & Not Effective & More Effective & More Effective & More Effective & More Effective \\
\hline Ultraviolet Disinfection & Not Effective & More Effective & Not Effective & Insufficient Data & Insufficient Data \\
\hline Advanced Oxidation & Less Effective & More Effective & Not Effective & More Effective & More Effective \\
\hline
\end{tabular}

by the Homeland Security Exercise and Evaluation Program (HSEEP) (US Department of Homeland Security, 2013) and focused explicitly on recovery of the distribution network. A centralized mind-mapping theme organized the thoughts created during the exercise. A mind-mapping expert effectively transfered the interconnectivity and centralized themes of the discussions (Margulies and Maal, 2002). As the decision making activities during the recovery process are nonlinear, this mind-mapping format translated well as an approach to organizing the thoughts generated during the tabletop exercises (Stephens and Hermus, 2007).

Participants engaged amongst themselves and with CIR researchers within an exercise that examined the decision making process which would occur during a simulated contamination event. Participants began the exercise at a point in the contamination narrative in which the contaminant ceased movement through the system and the situation was stable. From this point, they then generated a set of questions that must be answered in order to effectively make the correct decision. These questions became the critical decision points elicited from the exercise. Table 2 is a summary table of these decision points categorized by general areas of concern. Figure 2 presents the groups mind map.

\subsection{Network Decontamination Model (NDM)}

The NDM, a module to KYPipe and product of cooperation with the KWRRI at the University of Kentucky, addresses the spatial issues related to potential contamination events. KYPipe is a widely used commercial, water distribution modeling software. The NDM is a graphical utility that can generate a schematic of a utility's distribution system using preexisting geographic information system (GIS) data. The NDM analyzes the extent of contamination within the distribution network.

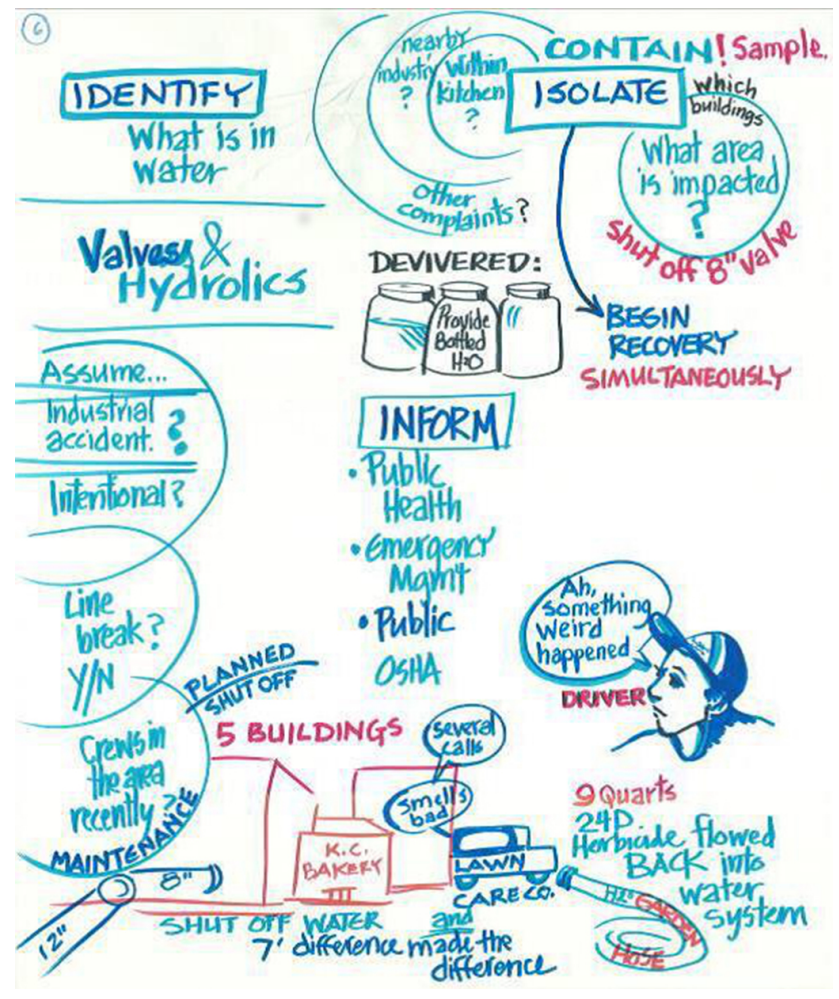

Figure 2. Mind map of hypothetical contamination scenario in which tabletop exercise participants determined key events and participant questions.

The Kentucky Infrastructure Authority's (KIA's) preexisting online portal of water infrastructure data, the Water Resources Information System (WRIS) (Kentucky Infrastructure Authority, 2013), prototypes the NDM and GIS interoperability. The WRIS database includes GIS information on pipelines, water tanks, water treatment plants, water meters, 
Table 2. Summarized decision points critical to response following a contamination event.

\begin{tabular}{ll}
\hline General Area of Concern & Decision Points \\
\hline Contaminant & (1) What is the contaminant? (2) Is the contaminant isolated to single site? Or impacting mul- \\
tiple sites? (3) Is the contaminant biological? Is it contagious? (4) What if the contamination \\
event occurs during inclement (freezing temperatures)? (5) Is this contaminant a vehicle for \\
another contaminant? (6) Is the type of contaminant known or unknown? (7) What are the en- \\
vironmental and public health risks with the associated contaminant?
\end{tabular}

Critical Customers (1) Have the vulnerable customers been identified? Do you have appropriate contact information for them? (2) How will impacted critical care customers be handled during long-term outages? Evacuation? Shelter in place? (3) What if a school is impacted? Alternative schools? (4) What are the short-term and long-term health effects of the contaminant on humans?

Infrastructure (1) Do we know the pipeline material affected by the contaminant? (2) What is the permeability of the pipeline? (3) What is the age of the affected pipeline? (4) Is there information on the contaminant's short-term and long-term impact on pipeline materials, valves and gaskets? (5) Is there information on the contaminant's interactions with permeable materials in the distribution system? (6) Are the locations of the existing pipelines and valves known? (7) Is there is a hydraulic model of the distribution system? (8) Can the impacted area be isolated quickly in an interconnected system? (9) What can remote-sensing systems provide? (10) Where does the utility's responsibility to clean impacted infrastructure end? At the meter? (11) What is the contaminant's impact on residential infrastructure and water-using appliances? Copper pipes? Water heaters? Ice makers? (12) Whose responsibility is it to replace or fix impacted residential infrastructure and appliances?

Communications

(1) How will communications be handled, including to internal personnel, to the public, to the business community and to elected and other government officials? (2) Which local government officials and offices need to be informed? (3) Who is responsible for internal, public and other communication activities during the recovery from this incident? (4) Who is responsible for communicating with the local critical customers (medical facilities, nursing homes, dialysis facilities, public school system) impacted by the event? (5) What state and local regulators (Division of Water, Emergency Management, Public Health, OSHA, and EPA) need to be informed? (6) What procedures have been previously developed for use during this type of emergency? (7) How would internal communication procedures change if normal communication links are disrupted? (8) How would it be determined if an advisory or public notification (such as boil water or do not use) needs to be issued for this incident? How would this occur without power and if normal communication media such as TV and radio outlets are unavailable? What alternative resources could be available to issue an advisory? (9) Where can you find information for release to the media regarding potential water contaminants? (10) How will the utility restore public confidence in the product provided? (11) How would the utility handle communications if the contamination incident was an accident versus intentional? (12) How does a utility discern between an intentional and accidental contamination event? 
Table 2. Continued.

\begin{tabular}{ll}
\hline General Area of Concern & Decision Points \\
\hline Alternative Water Sources & (1) Does the impacted utility have the capacity to supply potable water after the contamina- \\
tion event? If not, what are the alternative sources? (2) How will the alternative water sources \\
be provided during long-term outages? (3) Does the utility have recommended delivery meth- \\
ods? Central distribution location? Temporary lines? (4) Who will pay for providing alternative \\
water sources during long-term outages? Does this change if the contamination event was in- \\
tentional? (5) How will the impacted utility recoup the associated costs? (6) How will critical \\
care customers be supplied during long-term outages? (7) At what point can treatment facilities \\
be established? (8) How will fire protection services be addressed in the contaminated area?
\end{tabular}

Coordination

Business Continuity

(1) What agencies or groups will the utility coordinate with concerning recovery and remediation? (2) What are the expectations for their support? (3) What specific coordination procedures have been developed to ensure successful coordination?

(1) During emergency operations including recovery and remediation, what outside contract services are available to provide services? (2) What priority will your contractors give you if other business and city operations are competing for the same equipment or services? (3) Who is responsible for covering the cost of impacted equipment (ice makers, laboratory equipment and manufacturing equipment)? (4) How does the utility assist small businesses?

\begin{tabular}{ll}
\hline Logistics & (1) What procedures have been developed to address logistical support (e.g., food, shelter and \\
equipment for responders) during this incident? (2) What procedures and/or provisions are in \\
place to support personnel with special needs (e.g., lost or damaged personal property, injured \\
or killed family/friends and psychological impact from devastation) due to the incident? (3) If \\
service is out for a prolonged period, how is alternative water going to be provided to impacted \\
customers?
\end{tabular}

Mutual Aid/Assistance (MAA) (1) If your utility does not have enough personnel during the incident, what other options are available and have arrangements been made in advance? (2) How are you going to manage the demands for long-term recovery, and should these needs be addressed in your MAA agreement?

Law Enforcement

(1) What inspection or surveillance programs are in place to detect any physical security breaches in utility appurtenances, such as water storage facilities and the distribution system? Does your utility have a "neighborhood watch" or "water watchers" program in place within the served community?

Finance and Administration

(1) What procedures have been developed to address incident-related expenses? (2) How are financial and other incident records maintained? How will the lost revenue of impacted business be covered? What about the cost of lost products (food spoilage, contaminated products)? (4) Once a recovery plan is established, what is the financial impact on customers and the utility? (5) Will the utility's actions or inactions lead to legal liability?

and pump stations. A direct linkage to this repository exists within the NDM and allows the user to seamlessly download and generate a model for his or her distribution system. Figure 3 is an example NDM network model.

Functionally, the NDM provides the user with the ability to examine the spatial distribution of valves and hydrants, im- portant for either isolating the contaminant or for ex-situ remediation of the network. Users can alter contaminant spread through opening and closing the valves and hydrants. Additionally, the use of icons and backdrop maps visualize the locations of critical customers, such as hospitals and schools (Fig. 4). 


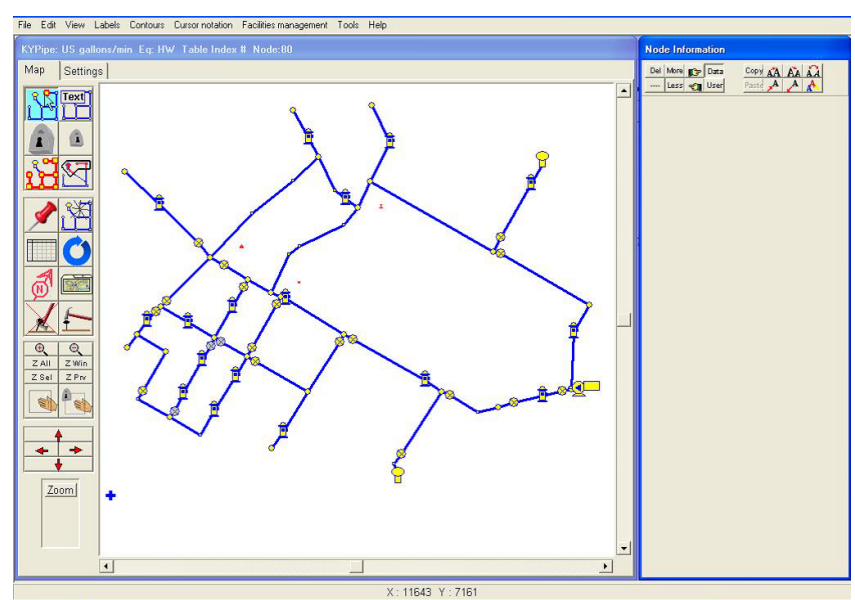

Figure 3. Example network in the Network Decontamination Model (NDM). The NDM is an extension to KYPipe, a commercially available, hydraulic modelling software.

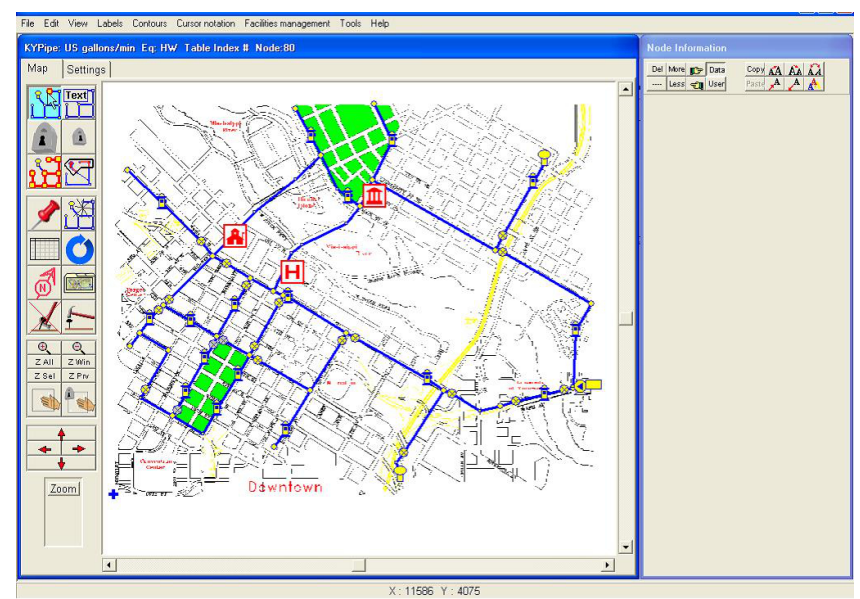

Figure 4. NDM with additional icons depicting the location of critical users and a backdrop map.

Once the NDM conceptualizes a full contamination event, the model calculates the volume of contaminated water, summarizes the valves and hydrants in the contamination area, identifies the age and material of pipe in the contamination area, and identifies the hydrant with the lowest elevation, important if the system is to be flushed. These outputs are then reported to the user, where he or she can either use the data independently or export it for use within Water Expert. Figure 5 is an example of hypothetical contamination event, created using the NDM (KYPipe and University of Kentucky, 2012).

The NDM constitutes the first instantiation of a mathematical model plugin developed for Water Expert. The outputs of an NDM run are exported into Water Expert to refine the knowledgebase and provide additional refinement of Water Expert recommendations.

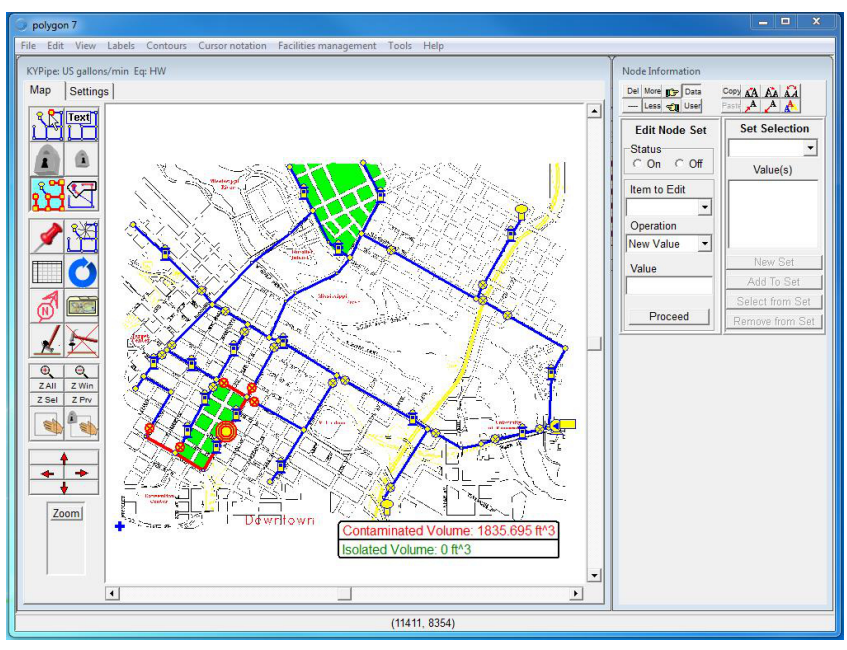

Figure 5. Example contamination event within the NDM.

\subsection{Rules Based Decision Support Tool (RBDST)}

The knowledgebase in Water Expert is a product of the guiding principles of knowledge engineering. According to McCorduck and Feigenbaum (1983), this philosophy takes the knowledge associated with complex problem-solving abilities, normally requiring an advanced level of human expertise, and converts this knowledge into a computerized format. The process of performing this conversion includes four steps: (1) information is gathered using literature reviews, workshops, and seminars; (2) information is extracted from these sources; (3) information is compounded into a taxonomical structure that comprises a knowledgebase; and (4) the knowledgebase is integrated into computerized modelling or simulation environment for functionality and additional knowledge extraction. The CWRS at Western Kentucky University and the EI at The University of Alabama developed the Water Expert knowledgebase. Water Expert unites data gathered during the initial literature review, state of the art decontamination report, tabletop exercises, and through discussions with an external advisory board of industry, regulatory, and trade association representatives. A MySQL relational database management system (RDBMS) holds the data (MySQL, 2014) and the Drupal 6 CMS brings the data to the user (Drupal, 2008). The CLIPS inference engine drives the rules and facts that comprise the knowledgebase (CLIPS, 2013).

\subsection{Technology deployment and implementation workshops}

Four deployment workshops evaluated the prototype version of Water Expert. Western Kentucky University, the University of Kentucky, and KYPipe hosted these workshops. Participants included water utility personnel, emergency preparedness representatives, public health officials, regional 
planners, and regulators. Training materials introduced participants to the software's functionality and guided him or her through usage of Water Expert and the NDM. Participants filled out two separate evaluation forms for each piece of software to solicit feedback on the presentation, the presentation materials, and the features of Water Expert.

Subsequent to the technology demonstration workshops, project personnel used the feedback gathered therein to refine the software and ultimately to develop a revised version of the prototype Water Expert. This refined product was then launched at three utilities who aided the research team in conceptualizing plausible contamination scenarios for formal validation. These three hypothetical contamination scenarios provided further demonstration and evaluation of the software's effectiveness.

\section{Results}

Water Expert includes both graphical tools and menus that allow the user to select the appropriate course of action relative to the nature and extent of contamination. Through a preferred web browser, users can access Water Expert. The primary target users are water utility managers or operators. Researchers assume that Water Expert will be useful to academics, regulators, public health officials, emergency preparedness representatives, and local and regional planners. The Water Expert code is separate from the core CMS installation and is a PHP modular extension to Drupal 6.

The following sections summarize the functionality of the system. Figure 6 is a system flow chart for the final software product that summarizes its functionality. The decision points provided in Table 2 constitute the basis of this system flowchart. Each of these portals are entrances where the user interacts with the Water Expert. They exist on the Drupal 6 CMS, the central hub of interaction with Water Expert. User input gathered at these portals become "local facts" that compare against the system-wide "global facts", derived from preceding subprojects. The CLIPS inference engine drives this comparison. All reports and recommendations are graphically output to the user using the CMS. The CMS is the $\mathrm{Wa}$ ter Expert user portal and provides the extensibility necessary to update and expand the knowledgebase. Fact and rule generation can occur on demand for the user, and engages the expert system inference engine.

Water Expert preliminarily addresses contaminants contained within the United States Environmental Protection Agency National Primary Drinking Water Regulations. The concentrations or amount of contaminants that provide warnings and recommendations by Water Expert are those believed to have an effect on both human (ATSDR, 2013; USEPA, 2013b) and environmental health (USEPA, 2014a). Technology recommendations come from findings of the USEPA. These findings address treatment effectiveness on specified species of contaminants, as previously depicted in

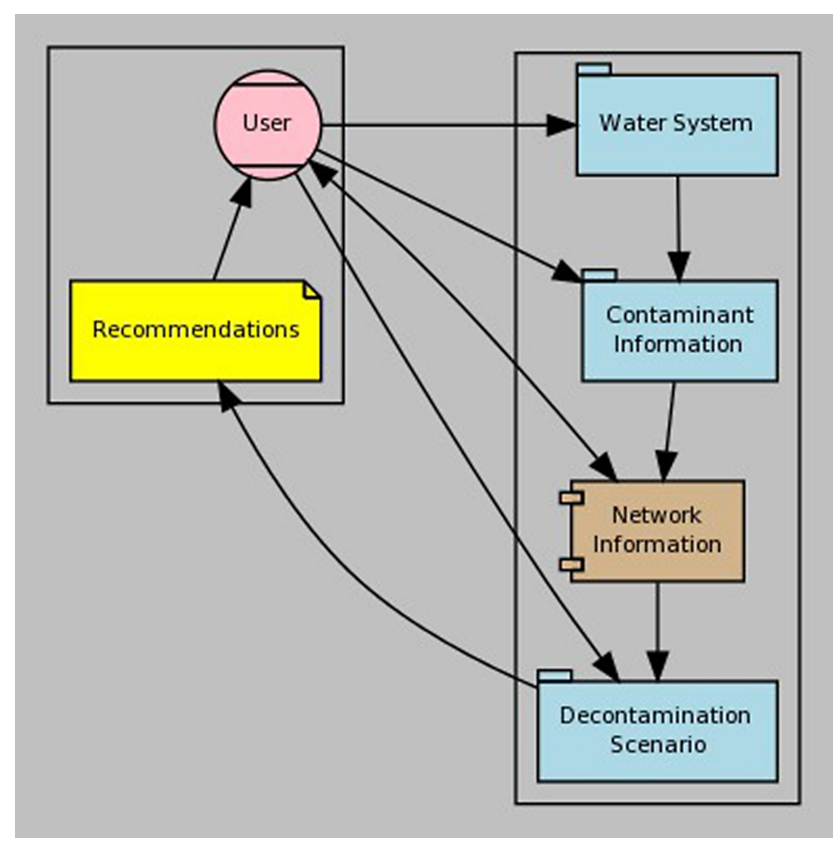

Figure 6. Water Expert decontamination system flowchart.

Table 1. Optionally, outputs from the NDM export to a CSV file for upload into Water Expert. These outputs upload into the MySQL RDBMS, and generate additional facts to compare against the knowledgebase. For example, this information interprets the possibility of contaminated piping material interacting with the contaminant(s) of interest.

The University of Missouri literature review and the University of Louisville table top exercise found that decisions made during contamination events are multi-faceted and multi-disciplinary. Concerns alluded to in Table 2 include inputs that consider contaminate characteristics, recovery timetables, infrastructure impact, public relations, government regulations, financial burden, logistics, mutual aid agreements, public health, environmental, social impact, and economic impact. Interaction with utilities throughout the development of Water Expert emphasized that water providers struggle to coalesce each of these concerns into informed actions. In many cases, water utilities will simply flush contaminated water from the system without considering secondary affects.

Though the current core incarnation of Water Expert does not fully address all of these concerns, the following sections detail that the system is capable of providing recommendations on contaminant characteristics, government regulations, public health, environmental health, infrastructure impact, and treatment alternatives. A condensed and easily readable report provides the recommendations. The researchers envision that such a report will guide the decision maker in addressing a subset of the issues detailed in Table 2.

If the user develops a KYPipe model, he or she can begin to gain a greater understanding of a particular contamination 


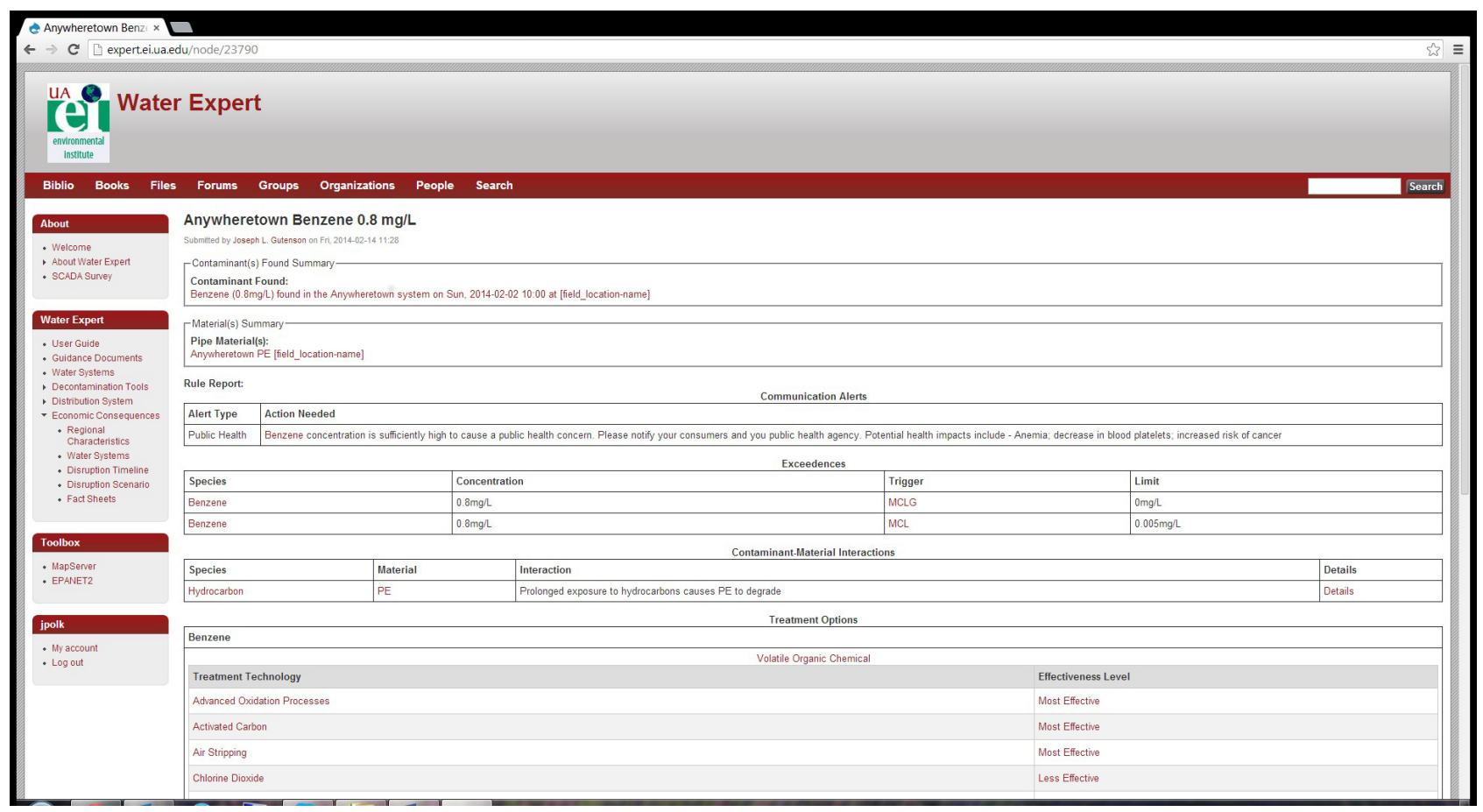

Figure 7. Example recommendation page generated by Water Expert.

event. With the NDM users can understand the spatial nature of a contamination event and may also estimate the number of pipes and volume of water which has been affected. This further drives the inference engine within Water Expert and augments the final report that Water Expert generates.

\subsection{User input and system output}

A four-step user-input process initiates through the CMS on a local web browser (Fig. 6). This process begins with guiding the user through developing a profile of her or his distribution system including name, administrative contact, address, population served, etc. These "Water System" data are not used by the analysis portion of the current system, but are an indexing mechanism to gather information pertinent to the contamination event. Information on the specific contaminant collects at the "Contaminant Information" portal where the user provides a detailed review of the contaminants found during the contamination event, including the location and concentration of the contaminant. Water Expert allows the user to either enter the network information manually or utilize the NDM. The system uses these data to determine whether network infrastructure will be degraded by the contaminant(s) of concern.

Along the data gathering pathway, facts are generated on demand and conglomerated at the "Decontamination Scenario" portal. Once this information is submitted, MySQL ports the generated facts to a server-side instance of CLIPS. CLIPS executes pattern matching between the "local facts" and "global facts". Once the system concludes its analysis, a "Recommendations" page instantiates and renders to the user on the CMS. Here the system warns the user of both the public and environmental health concerns, regulatory concentration exceedance, and contaminant-network material interaction. Water Expert additionally supplies a weighted list of treatment technologies to decontaminate the system. For a particular contaminant, the weighted list of treatment technologies communicates to the end user the uncertainty associated with the use of a particular treatment technology. Figure 7 is an example of these recommendations.

When the user has access to a KYPipe hydraulic model of their distribution system, the NDM augments Water Expert recommendations. The NDM output exports as a comma separated value (CSV) file which is then read by Water Expert. This NDM export file automatically feeds Water Expert with piping material for contaminant-pipe interaction. Additionally, the NDM export file provides summarization of the anticipated volume of contaminated water and number of pipes affected or the extent of the contamination in the "Recommendations" page. The system does not currently address workforce shortfalls, aside from providing a weighted listing of possible remediation measures.

\subsection{Fact and rule creation}

Facts created by both the user (local facts) and site administrators (global facts) through the CMS provides Water Expert with a guided protocol that facilitates the extensibility 
required to update and maintain the evolving knowledgebase. Using PHP code and the Drupal Content Creation Kit (CCK) (Drupal, 2013), CCK content types exist for each type of fact. For example, a Contaminant content type generates facts on the contaminants of interest. Data entered are then stored in the RDBMS and analyzed and synthesized by PHP into the fact format necessary for the CLIPS inference engine. Rules are also created in a similar fashion. The CMS also removes facts and rules. The CMS is this mechanism that provides flexibility to update and use knowledge in an expedited manner.

\subsection{Training, education and guidance}

Prescribed pathways within the CMS represent pre-defined endpoints for typical use cases. These pathways streamline the knowledge retrieval process and simplify user interaction. Fact sheets provide information on USEPA-regulated contaminants and consist of pre-packaged content, which can be retrieved through point and click interaction with the CMS. These fact sheets provide rapid access and address specific aspects of a contaminant(s) of concern. Additionally, interactive guidance documents allow the end-user to peruse decontamination information in a self-determined sequence. Information in guidance documents present hierarchical access with increasing detail. An installation of GraphViz (2014) engages interactive guidance, presenting the user with flowchart visualization. Figure 8 is an example of the interactive GraphViz charts used to navigate the guidance documents.

\section{Case study}

In order to illustrate the functionality of the system in its current capacity, envision a city named Anywheretown, located adjacent to a major interstate. In this town, the risk of possible chemical spills caused by vehicular wrecks is high. In several US states, a large portion of accidents involving hazardous chemical spills involve those with petroleum oils and fuels (Becker et al., 2000; Golla et al., 2012). Therefore a spill, intentional or unintentional, involving gasoline is a plausible scenario.

Assuming that such an event occurs and that, insufficient cleanup activities are performed at the spill site allow the gasoline to remain within the soil matrix and interact with nearby water distribution system piping. Ong et al. (2010) and the American Water Works Association (AWWA) and Economic \& Engineering Services, Inc. (2002) demonstrate that this incident will cause thermoplastic piping (polyethylene (PE), polyvinyl chloride (PVC), etc.) to degrade and allow the substance to permeate the piping. Assuming that the Anywheretown distribution system is entirely comprised of polyethylene and the piping is relatively new, this degradation process would usually occur on the order of several weeks.

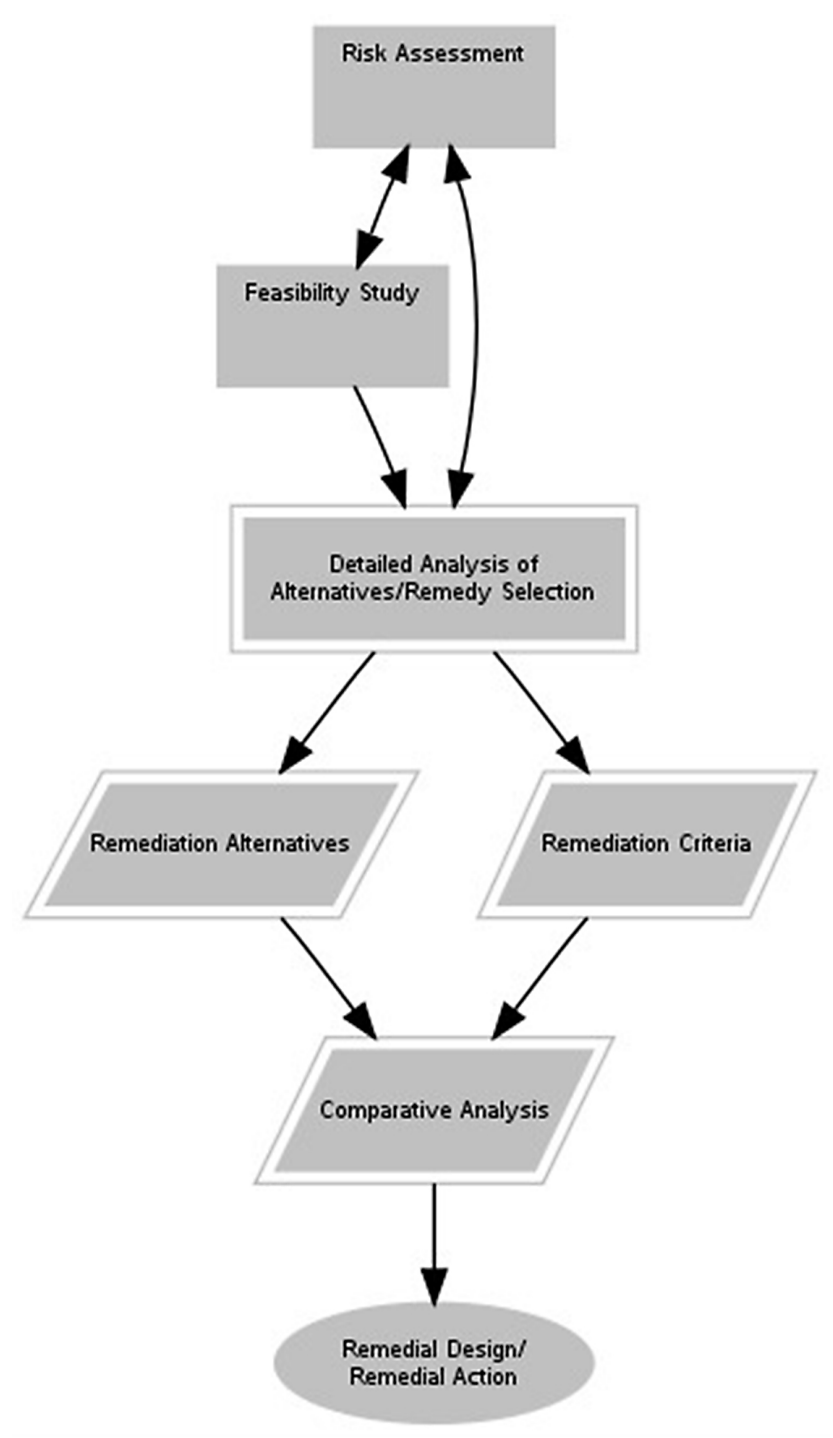

Figure 8. Interactive flowcharts used to navigate the guidance documents. This particular example is based on content derived from USEPA (2004c).

However, for the substance to enter the distribution system, a sufficient drop in pressure at the point of contamination must have occurred. Such a drop in pressure may be the result of a system ill-prepared to supply fire flow, a part of the system being taken offline which isolates sections of the network from service, system pumps going down, and/or intrusion events (Fleming et al., 2005; Besner et al., 2010). Thus, one of these events drove the network to zero or negative pressure at the point of injection, allowing the contaminant to permeate the polyethylene piping and enter the distribution system.

The Anywheretown Water Department then begins receiving taste and odor complaints from customers in the general vicinity of the spill location. Testing reveals that Benzene, a major constituent of gasoline is present at a $0.8 \mathrm{mg} \mathrm{L}^{-1}$ con- 
Table 3. Anywheretown example data inputs into Water Expert.

\begin{tabular}{|c|c|c|}
\hline \multirow[t]{2}{*}{$\begin{array}{l}\text { Water System } \\
\text { Location }\end{array}$} & \multicolumn{2}{|c|}{$\begin{array}{l}\text { Anywheretown } \\
\text { Interstate }\end{array}$} \\
\hline & Contaminant Information & Network Information \\
\hline Contaminant & Benzene & \\
\hline Concentration & 0.8 & \\
\hline Concentration Units & $\mathrm{mg} \mathrm{L}^{-1}$ & \\
\hline Date and Time & 2/14/2014 10:00 CST & \\
\hline Material & & Polyethylene \\
\hline
\end{tabular}

Table 4. Benzene contamination alert.

\begin{tabular}{ll}
\hline Alert Type & Action Needed \\
Public Health & Benzene concentration is sufficiently \\
& high to cause a public health concern. \\
& Please notify your consumers and you \\
public health agency. Potential health & impacts include - Anemia; decrease in \\
blood platelets; increased risk of cancer
\end{tabular}

centration. Unsure of what to do, the Anywheretown decision makers consult the Water Expert system about the situation, entering into Water Expert the data found in Table 3. The content type categorizes these inputs. Water System and Decontamination Scenario information are excluded from this table as they are only used as an indexing mechanism. Network Information was added manually, in lieu of no available network information.

The inputs generate the summarized recommendation in Tables 3, 4, 5, and 6. These tables demonstrate Water Expert's ability to summarize the data found to be critical to the decontamination process by the University of Missouri literature review. The decision points found as part of the tabletop exercises conducted by the University of Louisville.

\section{Further research}

Present capacity to offer decontamination assistance will be complimented with the development of tools which will perform comprehensive examination of the economic effects of disruptions in water service (Alva-Lizarraga and Johnson, 2012; Gutenson et al., 2013). Additionally, tools to help utilities develop monitoring and control systems for their distribution network are under development. Supplementary projects intend to address capacity development issues for infrastructure systems, such as Asset Management and ERP development. Additionally, embedded hydraulic modelling and integrated GIS will be used to expand Water Expert's capabilities. These upgrades will work to address a broader range of issues detailed in Table 2 .

Each individual summary prepared in the literature review will extend the knowledgebase of Water Expert in the form of facts and rules. These additions will augment the existing fact and rule base and provide drill down capabilities within $\mathrm{Wa}$ -
Table 5. Benzene exceedence alert.

\begin{tabular}{llll}
\hline Species & Concentration & Trigger & Limit \\
\hline Benzene & $0.8 \mathrm{mg} \mathrm{L}^{-1}$ & MCLG & $0 \mathrm{mg} \mathrm{L}^{-1}$ \\
Benzene & $0.8 \mathrm{mg} \mathrm{L}^{-1}$ & MCL & $0.005 \mathrm{mg} \mathrm{L}^{-1}$ \\
\hline
\end{tabular}

Table 6. Benzene contaminant-material interactions.

\begin{tabular}{lll}
\hline Species & Material & Interaction \\
\hline Hydrocarbon & Polyethylene (PE) & $\begin{array}{l}\text { Prolonged exposure to } \\
\text { hydrocarbons causes } \\
\text { PE to degrade }\end{array}$ \\
\hline
\end{tabular}

ter Expert for users who desire more descriptive information. An example of this functionality is the system's current ability to recognize the interaction between hydrocarbons, such as diesel and gasoline fuels, with thermoplastic piping.

The system is moving from a web-deployed environment to a localized, enterprise-wide cloud based system, similar to that depicted in Fig. 9. Concerns voiced by utility and trade association representatives who hesitate to place sensitive data in a remote database, drive this migration. Thus, future iterations of Water Expert will take advantage of the concept's adaptive nature and will transition to fat-client applications installed on user's local machines and interact with local databases. This new format will be designed to interact with a utility's local databases and supply them with recommendations at an institutional level. Inputs and outputs supplied to the system through utility representative's mobile and desktop hardware facilitate immediate feedback and response among all members of the organization.

Abroad, similar on-going efforts in the European Union include ISIS, TAWRA_RTM, CATO, Safewater Project and Secureau. Secureau and the Safewater Project focus on developing methods, tools, and mathematical models by which contaminant mitigation can best be achieved (Science Daily, 2013; Safewater Project, 2014). CATO is a project designed to provide computerized decision support through integration with water networks existing systems (CATO, 2012). TAWARA_RTM focuses on developing real time radionuclide sensor networks (TAWARA_RTM, 2015) ISIS is developing a sensor-based risk analysis system for intelligent remediation following contamination events (ISIS, 2015). Each of these provide valuable collaboration opportunities to enhance the core decontamination module of Water Expert.

Further, the nature of the system allows for its use in other areas including natural hazards, such as flooding events, to provide decision makers with recommendations and summaries to complement their actions during these calamities. 
Table 7. Benzene Treatment Options based on USEPA (2004c).

\begin{tabular}{ll}
\hline Treatment Technology & Effectiveness Level \\
\hline Advanced Oxidation Process & Most Effective \\
Activated Carbon & Most Effective \\
Air Stripping & Most Effective \\
Chlorine Dioxide & Less Effective \\
Chlorination & Less Effective \\
Ozonation & Less Effective \\
Ultraviolet (UV) Disinfection & Less Effective \\
Microfiltration, Ultrafiltration & Not Effective \\
Reverse Osmosis (RO) and Nanofiltration (NF) & Not Effective \\
Coagulation/Filtration & Not Effective \\
Ion Exchange & Not Effective \\
Activated Alumina (AA) & Insufficient Data \\
Chloramination & Insufficient Data \\
Direct Filtration & Insufficient Data \\
\hline
\end{tabular}

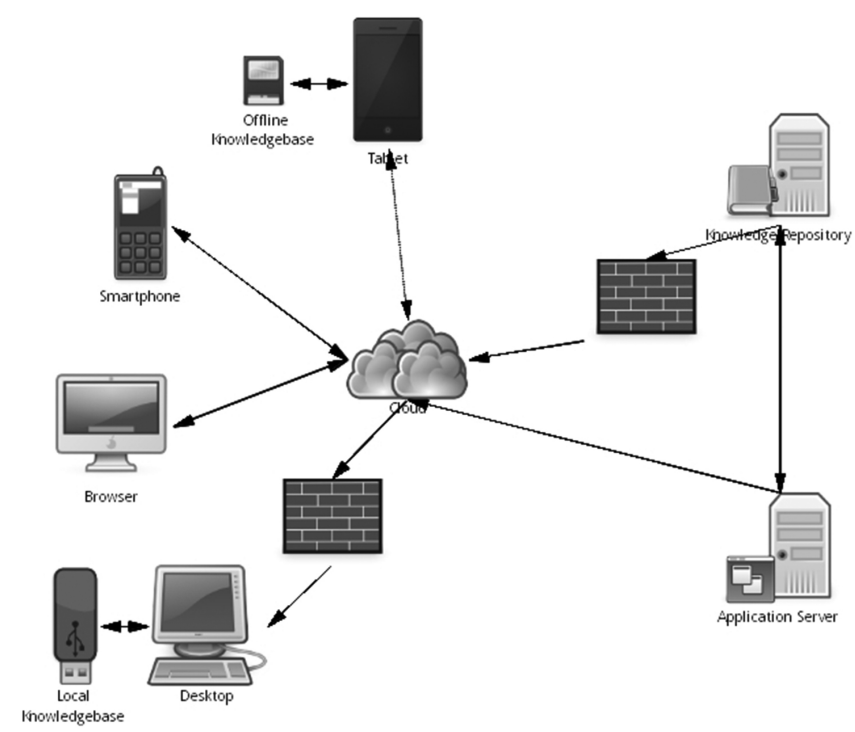

Figure 9. Future cloud deployed environment of Water Expert. It is envisioned that this environment will exist as a local, enterprise level system for individual utilities.

\section{Conclusions}

Decisions made during contamination events are multifaceted and multi-disciplinary. Utilities detail that they face a broad spectrum of challenges when in the midst of a contamination event. During these episodes, water utilities must consider contaminate characteristics, recovery timetables, infrastructure impact, public relations, government regulations, financial burden, logistics, mutual aid agreements, public health, environmental, social impact, and economic impact. In time sensitive environments, water providers struggle to coalesce each of these concerns into informed actions. In many cases, water utilities will absolve to utilize the most available means of mitigating contamination, without considering all aspects of the decision made.
The functionality of Water Expert serves to provide a comprehensive set of tools for which the user can explicitly determine the most viable pathway for decontamination following a contamination event. Water Expert provides recommendations by generating a local fact base derived from the user and compares this information to the knowledgebase of global facts and rules using the CLIPS pattern matching, inference engine. This system facilitates interaction with the user through an online instance of the Drupal 6 CMS, with an embedded CLIPS expert system shell. Water Expert generates public and environmental health warnings, determines if concentrations exceed regulatory limits, and assesses effectiveness of a wide range of commonly utilized treatment technologies. Additionally, the system provides pre-defined endpoints representing the typical use cases. These pre-defined end points currently exist in the form of fact sheets provided for all USEPA regulated contaminants and interactive guidance documents that guide the user through the decontamination process.

The development of this tool has involved most, if not all, key stakeholder groups in every step of the creative process. From the literature review which tapped into the academic and research aspects of the decontamination process, to the series of tabletop and demonstration workshops that provided hands-on opportunities for practitioners in the water industry. The schema allows the researchers to identify the critical needs of the industry and align them with the overarching development goals for Water Expert. This form of development has created a living application that can grow and adapt with the dynamics of the industry.

Key to the functionality of Water Expert is its adaptability. The conceptual framework of the system has allowed researchers to integrate Water Expert with third-party applications, like the NDM, which opens the door for more robust coupling of models from an assortment of academic disciplines. Intuitively, with this expansion will come an increase in the data available for the inference engine to process, likely promoting a more attuned set of recommendations. To this end, the functionality of Water Expert is also completely independent of any software that it currently utilizes. Thus, while a functional system, the schematic of the system can adapt to any necessary changes that arise.

Like many previous hybrid DSS/expert system applications, the system demonstrates the ability to meld heuristic decision making with procedural models. Water Expert is novel in that it utilizes the outputs of the NDM to inform the user on decontaminating their distribution system. No prior DSS applications have provided the ability to inform WDNs during contamination events. This aspect of the system is modular as the spectrum of end users is encompassed by the platform. Thus, the system is not limited to WDNs heavily invested in cyber infrastructure. The Water Expert framework comprises an initial step at providing decontamination assistance to all WDNs. Though not novel in concept, 
the framework is the first of its kind to attempt at providing decontamination assistance for WDNs.

Acknowledgements. The US Department of Homeland Security (DHS), Science \& Technology Directorate, provided funding for this project through a technology development and deployment program managed by The National Institute for Hometown Security (NIHS).

Edited by: L. Rietveld

\section{References}

Agency for Toxic Substances \& Disease Registry (ATSDR): http:// www.atsdr.cdc.gov/mrls/index.asp (last access: 30 March 2014), 2013.

Ahn, B. S., Cho, S. S., and Kim, C. Y.: The integrated methodology of rough set theory and artificial neural network for business failure prediction, Expert Syst. Appl., 18, 65-74, doi:10.1016/S0957-4174(99)00053-6, 2000.

Alva-Lizarraga, S. and Johnson, T. G.: A dynamic demand driven, supply constrained input output approach to modeling economic impacts of water disruption events, 2012 Conference Proceedings, Mid-Continent Regional Science Association, Ottawa, Canada, 6-8 June 2012, 159-177, 2012.

American Water Works Association (AWWA) and Economic and Engineering Services, Inc.: Permeation and leaching, US Environmental Protection Agency, Washington, DC, 22 pp., 2002.

Bahrammirzaee, A.: A comparative survey of artificial intelligence applications in finance: Artificial neural networks, expert system and hybrid intelligent systems, Neural Comput. Appl., 19, 11651195, doi:10.1007/s00521-010-0362-z, 2010.

Becker, S. M., Pitt, R., and Clark, S.: Environmental health, public safety, and social impacts associated with transportation accidents involving hazardous substances, Project Summary, University Transportation Center for Alabama, Tuscaloosa, AL, 192 pp., 2000.

Besner, M. C., Ebacher, G., Jung, B. S., Karney, B., Lavoie, J., Payment, P., and Prévost, M.: Negative pressures in full-scale distribution system: field investigation, modelling, estimation of intrusion volumes and risk for public health, Drink. Water Eng. Sci., 3, 101-106, doi:10.5194/dwes-3-101-2010, 2010.

Drupal: https://drupal.org/drupal-6.0 (last access: 31 March 2014), 2008.

Drupal: https://drupal.org/project/cck (last access: 30 March 2014), 2013.

CATO: http://www.cato-project.eu/ (last access: 10 June 2015), 2012.

Chang, N., Pongsanone, N. P., and Ernest, A.: A rule-based decision support system for sensor deployment in small drinking water networks, J. Clean. Prod., 29-30, 28-37, doi:10.1016/j.jclepro.2012.02.010, 2012a.

Chang, N., Prapinpongsanone, N., and Ernest, A.: Optimal sensor deployment in a large-scale complex drinking water network: Comparisons between a rule-based decision support system and optimization models, Comput. Chem. Eng., 43, 191199, doi:10.1016/j.compchemeng.2012.03.012, 2012 b.
CLIPS: A Tool for Building Expert Systems: http://clipsrules. sourceforge.net/ (last access: 31 March 2014), 2013.

Delen, D. and Pratt, D. B.: An integrated and intelligent DSS for manufacturing systems, Expert Syst. Appl., 30, 325-336, doi:10.1016/j.eswa.2005.07.017, 2006.

Engelmore, R. S. and Feigenbaum, E.: Expert systems and artificial intelligence, in: Knowledge Based Systems in Japan, edited by: Engelmore, R. S., Loyola College in Maryland, Baltimore, Maryland, 1993.

Feinsten, J. L. and Hadden, S. G.: Introduction to expert systems, J. Policy Anal. Manag., 8, 182-187, doi:10.1002/pam.4050080202, 1989.

Fleming, K. K., Gullick, R. W., Dugandzic, J. P., and LeChevallier, M. W.: Susceptibility of potable water distribution systems to negative pressure transients, New Jersey Department of Environmental Protection, Trenton, NJ, 55 pp., 2005.

Fonseca, D. J., Navaresse, D. O., and Moynihan, G. P.: Simulation metamodeling through artificial neural networks, Eng. Appl. Artif. Intel., 16, 177-183, doi:10.1016/S0952-1976(03)00043-5, 2003.

Golla, V., Taylor, R., Suhl, J., Eagleson, J., Chavan, P., Grigsby, R., and Bottom, J.: Louisville/ Jefferson county hazardous material commodity flow analysis, Kentucky Division of Emergency Management, Frankfort, KY, 142 pp., 2012.

Graphviz - Graph Visualization Software: http://graphviz.org/, last access: 30 March 2014.

Gutenson, J. L., Ernest, A., Oubeidillah, A. A., and Zhang, X.: Development of a python enabled software application for assessing economic impacts of disruptions in water service, Alabama Water Resources Association Conference, Orange Beach, AL, \#46, September 2013.

ISIS: http://isis-project.eu/news-items, last access: 10 June 2015.

Kentucky Infrastructure Authority (KIA): http://kia.ky.gov/wris/ data.htm (last access: 30 March 2014), 2013.

Kisi, O., Akbari, N., Sanatipour, M., Hashemi, A., Teimourzadeh, K., and Shiri, J.: Modeling of dissolved oxygen in river water using artificial intelligence techniques, Journal of Environmental Informatics, 22, 92-101, doi:10.3808/jei.201300248, 2013.

KYPipe: http://kypipe.com/decon, last access: 31 March 2014.

KYPipe and University of Kentucky: NDM: Network decontamination model user's manual. KYPipe, LLC \& The University of Kentucky, Lexington, KY, 84 pp., 2012.

Margulies, N. and Maal, N.: Mapping Inner Space: Learning and teaching visual mapping, 2nd Edn., Corwin, Newbury Park, CA, 160 pp., 2002.

McCorduck, P. and Feigenbaum, E. A.: The Fifth Generation: Artificial intelligence \& Japan's Computer Challenge to the World, Addison Wesley Publishing Company, Reading, MA, 288 pp., 1983.

Moynihan, G. P.: Web-based expert system for foundry pollution prevention, SPIE Proceedings 5262, Environmentally Conscious Manufacturing III, Providence, RI, 27 February 2004, 2004.

Moynihan, G. P., Saxena, P., and Fonseca, D. J.: Development of a decision support system for procurement operations, International Journal of Logistics Systems and Management, 2, 1-18, 2006.

Murray, R., Janke, R., and Uber, J.: The threat ensemble vulnerability assessment (TEVA) program for drinking water distribution system security, Proceedings of the 2004 World Water and En- 
vironmental Resources Congress, 2004 World Water Congress, Salt Lake City, Utah, 27 June to 1 July 2004, 1-8, 2004.

Murray, R., Haxton, T., Janke, R., Hart, R., Berry, J., and Phillips, C.: Sensor network design for drinking water contamination warning systems: A compendium of research results and case studies using the TEVA-SPOT software, US Environmental Protection Agency, Cincinnati, OH, 80 pp., 2010.

MySQL: http://www.mysql.com/, last access: 31 March 2014.

Nemati, H. R., Steiger, D. M., Iyer, L. S., and Herschel, R. T.: Knowledge warehouse: An architectural integration of knowledge management, decision support, artificial intelligence and data warehousing, Decis. Support Syst., 33, 143-161, doi:10.1016/S0167-9236(01)00141-5, 2002.

Nourani, V., Baghanam, A. H., and Gebremichael, M.: Investigating the ability of artificial neural network (ANN) models to estimate missing rain-gauge data, Journal of Environmental Informatics, 19, 38-50, doi:10.3808/jei.201200207, 2012.

Ong, S. K., Gaunt, J., and Mao, F.: Impact of hydrocarbons on $\mathrm{PE} / \mathrm{PVC}$ pipes and pipe gaskets, AWWARF, Denver, CO, 232 pp., 2010.

Panda, S. S., Garg, V., and Chaubey, I.: Artificial neural networks application in lake water quality estimation using satellite imagery, Journal of Environmental Informatics, 4, 65-74, doi:10.3808/jei.200400038, 2004.

Purkait, B., Kadam, S. S., and Das, S. K.: Application of artificial neural network model to study arsenic contamination in groundwater of malda district, eastern india, Journal of Environmental Informatics, 12, 140-149, doi:10.3808/jei.200800132, 2008.

Rene, E. R., Joo, K. S., and Park, H. S.: Experimental results and neural prediction of sequencing batch reactor performance under different operational conditions, Journal of Environmental Informatics, 11, 51-61, doi:10.3808/jei.200800111, 2008.

Safewater Project: https://www.safewater-project.eu/ (last access: 10 June 2015), 2014.

Sandeep, K. and Rakesh, K.: CLIPS based decision support system for water distribution networks, Drink. Water Eng. Sci., 4, 37-50, doi:10.5194/dwes-4-37-2011, 2011.

Sandia National Laboratories: https://software.sandia.gov/trac/spot (last access: 31 March 2013), 2010.

Science Daily: www.sciencedaily.com/releases/2013/07/ 130704094851.htm (last access: 9 June 2015), 2013.

Shen, W., Guo, X., Wu, C., and Wu, D.: Forecasting stock indices using radial basis function neural networks optimized by artificial fish swarm algorithm, Knowl.-Based Syst., 24, 378-385, doi:10.1016/j.knosys.2010.11.001, 2011.

Stephens, P. and Hermus, C.: Making art connections with graphic organizers, The Art Education Magazine for Teacher, 106, p. 55, 2007.

Suribabu, C. R. and Neelakantan, T. R.: Particle swarm optimization compared to other heuristic search techniques for pipe sizing, Journal of Environmental Informatics, 8, 1-9, doi:10.3808/jei.200600072, 2006.

TAWARA_RTM: http://www.caen.it/csite/CaenProfList.jsp? parent=_173\&Preview=_Y, last access: 10 June 2015.

US Department of Homeland Security: Homeland Security Exercise and Evaluation Program (HSEEP), US Department of Homeland Security, Washington, DC, 2013.
US Department of Homeland Security: Homeland Security Exercise and Evaluation Program (HSEEP), US Department of Homeland Security, Washington, DC, 2013.

US Environmental Protection Agency (USEPA): EPA/State joint guidance on sanitary surveys, US Environmental Protection Agency, Washington, DC, 1995.

US Environmental Protection Agency (USEPA): Implementation guidance for the interim enhanced surface water treatment rule, EPA 816-R-01-011, US Environmental Protection Agency, Washington, DC, 2001.

US Environmental Protection Agency (USEPA): Instructions to assist community water systems in compliance with public health security and bioterrorism preparedness and response act of 2002, EPA 810-B-02-001, US Environmental Protection Agency, Washington, DC, 2002a.

US Environmental Protection Agency (USEPA): http://water.epa. gov/infrastructure/watersecurity/lawsregs/bioterrorismact.cfm (last access: 30 March 2014), 2002b.

US Environmental Protection Agency (USEPA): Vulnerability assessment factsheet, EPA 816-F-02-025, US Environmental Protection Agency, Washington, DC, 2002c.

US Environmental Protection Agency (USEPA): Overview and application, EPA 817-D-03-007, US Environmental Protection Agency, Washington, DC, 2003a.

US Environmental Protection Agency (USEPA): Large water system emergency response plan outline: Guidance to assist community water systems in complying with the public health security and bioterrorism preparedness and response act of 2002, EPA 810-F-03-007, US Environmental Protection Agency, Washington, DC, 2003b.

US Environmental Protection Agency (USEPA): Module 1: Water utilities planning guide, EPA 817-D-03-001, US Environmental Protection Agency, Washington, DC, 2003c.

US Environmental Protection Agency (USEPA): Module 2: Contamination threat management guide, EPA 817-D-03-002, US Environmental Protection Agency, Washington, DC, 2003d.

US Environmental Protection Agency (USEPA): Module 3: Site characterization and site guide, EPA 817-D-03-003, US Environmental Protection Agency, Washington, DC, 2003e.

US Environmental Protection Agency (USEPA): Module 4: Analytical guide, EPA 817-D-03-004, US Environmental Protection Agency, Washington, DC, $2003 \mathrm{f}$.

US Environmental Protection Agency (USEPA): Emergency response plan guidance for small and medium community water systems, EPA 816-R-04-002, US Environmental Protection Agency, Washington, DC, 2004a.

US Environmental Protection Agency (USEPA): Module 5: Public health response guide, EPA 817-D-03-005, US Environmental Protection Agency, Washington, DC, 2004b.

US Environmental Protection Agency (USEPA): Module 6: Remediation and recovery guide, EPA 817-D-03-006), US Environmental Protection Agency, Washington, DC, 2004c.

US Environmental Protection Agency (USEPA): Response guidelines, EPA 817-D-04-001, US Environmental Protection Agency, Washington, DC, 2004d.

US Environmental Protection Agency (USEPA): Decontamination and recovery planning: Water and wastewater utility case study, EPA 817-F-08-004, US Environmental Protection Agency, Washington, DC, 2008. 
US Environmental Protection Agency (USEPA): Containment and disposal of large amounts of contaminated water: A support guide for water utilities, EPA 817-B-12-002, US Environmental Protection Agency, Washington, DC, 2012.

US Environmental Protection Agency (USEPA): http://water. epa.gov/scitech/datait/databases/wcit/index.cfm (last access: 31 March 2014), 2013a.

US Environmental Protection Agency (USEPA): http://water.epa. gov/drink/contaminants/ (last access: 31 March 2014), 2013b.

US Environmental Protection Agency (USEPA): http://water.epa. gov/scitech/swguidance/standards/criteria/current/index.cfm, last access: 31 March 2014a.

US Environmental Protection Agency (USEPA): http: //cfpub.epa.gov/si/si_public_record_report.cfm?address=_nhsrc/ \&dirEntryId=_218488, last access: 31 March 2014b.

US Environmental Protection Agency (USEPA): http: //cfpub.epa.gov/si/si_public_record_report.cfm?dirEntryId= _253555\&fed_org_id=_1253\&address=_nhsrc/si/\&view= _desc\&sortBy=_pubDateYear\&showCriteria=_1\&count= _25\&searchall=_\%27water\%20security $\% 27$, last access: 31 March 2014c.
Water Research Foundation: Guidance for decontamination of water system infrastructure, No. 2981, Water Research Foundation, Denver, CO, 2009.

Water Sector Coordinating Council: Critical infrastructure and key resources sector-specific plan as input to the national infrastructure protection plan, EPA 817-R-07-001, US Environmental Protection Agency, Washington, DC, 2007.

Water Sector Decontamination Working Group: Recommendations and proposed strategic plan: Water sector decontamination priorities, American Water Works Association, Denver, CO, 2008. 